\title{
Toxicity Study to Determine Changes in Physiological Vital Parameters and Lethal Dose of Moringa Oleifera Found in Sokoto Metropolis Using Albino Rats Models
}

\author{
Ibrahim Maina Hassan ${ }^{1}$, Bashir Saidu', Ja'afaru Abdullahi Ishaq ${ }^{1}$, Ashiru Dahiru', \\ Nafisat Abdulazeez ${ }^{1}$, Halima Ibrahim Yusuf ${ }^{1}$, Umar Aliyu Dikko ${ }^{1}$, Bulama Ibrahim ${ }^{2}$, \\ Adama Musa Abdullahi ${ }^{3}$ \\ ${ }^{1}$ Department of Veterinary Physiology and Biochemistry, Faculty of Veterinary Medicine, Usmanu Danfodiyo University Sokoto, Sokoto, \\ Nigeria \\ ${ }^{2}$ Department of Veterinary Physiology and Biochemistry, Faculty of Veterinary Medicine, University of Maiduguri, Borno, Nigeria \\ ${ }^{3}$ Department of Veterinary Medicine, Faculty of Veterinary Medicine, University of Maiduguri, Borno, Nigeria
}

Email address:

Ibrahim.hassan@udusok.edu.ng (I. M. Hassan)

To cite this article:

Ibrahim Maina Hassan, Bashir Saidu, Ja'afaru Abdullahi Ishaq, Ashiru Dahiru, Nafisat Abdulazeez, Halima Ibrahim Yusuf, Umar Aliyu Dikko, Bulama Ibrahim, Adama Musa Abdullahi. Toxicity Study to Determine Changes in Physiological Vital Parameters and Lethal Dose of Moringa Oleifera Found in Sokoto Metropolis Using Albino Rats Models. Biochemistry and Molecular Biology.

Vol. 6, No. 1, 2021, pp. 7-10. doi: 10.11648/j.bmb.20210601.12

Received: May 22, 2020; Accepted: June 4, 2020; Published: February 23, 2021

\begin{abstract}
Epidemiological studies have indicated that Moringa oleifera leaves are good source of nutrition and exhibit antioxidant activities. This study is carried out to evaluate the effect of Moringa oleifera leaf extract on physiological vital parameters, Including Temperature, Respiratory rate and Heart rate. Twenty adult Wistar albino rats were used for this study. Animals were divided into four groups (A, B, C and D) of five animals each. Group A served as the control and was administered distilled water; the experimental groups B, C and D were administered different graded doses of Moringa oleifera leaf extract as follows $2000 \mathrm{mg} / \mathrm{kg}, 1000 \mathrm{mg} / \mathrm{kg}$ and $500 \mathrm{mg} / \mathrm{kg}$ orally for period of twenty four hours. The vital parameters were monitored and recorded after every two hours for the first eight hours and there after four hour interval for twenty four hours. The result of this study shows slight variation in body temperature between the control group and the group exposed to different concentration of the crude extract. There was significant changes in the Heart and respiratory rate of the rats in the treated groups compare to the control group. Extract from this plant can be used as anti-hypertensive agent.
\end{abstract}

Keywords: Anti-hypertensive Agent, Crude Extract, Heart Rate, Moringa oleifera, Respiratory Rate and Temperature

\section{Introduction}

Epidemiological studies have indicated that Moringa oleifera leaf is a good source of nutrition and exhibit antioxidant activities [1]. The plant is being used for many medical and nutritional purposes, since it is widely consumed by all for nutritional and varying medical purposes [2]. Although it has been widely used as a source of food, extracts from this plant have also been used for centuries in traditional medicine for the treatment of skin diseases, respiratory illnesses, ear and dental infections, hypertension, diabetes, cancer treatment, water purification and as nutrient supplementation [3]. Research on mineral composition of "Togolese ecotype" Moringa oleifera leaf and its effect on anthropometric parameters, atherogenic lipids and glycaemia during of HIV positive malnourished patients in Togo shows significant decrease of serum levels of total cholesterol, triglycerides, LDL-C correlated with significant increase in HDL-C [4]. Study of antioxidant, anticoagulant, platelet antiaggregatory and anti-inflammatory effect of Moringa oleifera on experimental rat model reported high potential with hydroalcoholic leaf extract [5]. Decreased blood glucose following administration of $50 \mathrm{~g} \mathrm{M}$. oleifera leaf powder in standard feed of diabetic induced rat model was documented. The outcome shows the potential of $M$. oleifera leaf powder to reduce $21 \%$ 
glucose concentration following one dose administration [6]. Acute toxicity study to evaluate the adverse effects of crude extract on animal model following single or multiple doses administration for twenty four hours or more by oral, dermal or inhalation were reported [7]. However, there is limited scientific data available regarding excessive consumption of this plant. Despite the growing number of research studies involving assessment of acute toxicity of $M$. oleifera primarily on rodents, the online lethal doses reported so far were different. Hence, the aim of this study is to assess the toxicity of $M$. oleifera methanolic leaf extract on albino rat.

\section{Materials and Method}

\subsection{Study Area}

Sokoto state is located at the extreme north-western part of Nigeria. It shares common boarders with Niger republic to the north and Kebbi State to the south-west, Zamfara State to the east. The dominant geographical features in the state are the river Rima, Sokoto River and their tributaries. The climate is a tropical continental type dominated by two opposite air masses; long dry windy and dusty season spanning from October to May which alternate with short rainy season from June to September. The average temperature is $20-40^{\circ} \mathrm{C}$ during the day with humidity less than $20 \%$.

\subsection{Equipment}

The equipment used was obtained at the Department of Physiology and Biochemistry Faculty of Veterinary Medicine Usmanu Danfodiyo University Sokoto. These include: Weighing balance, Syringe, Cannula, Hand gloves, Conical flask, Beaker, Refrigerator, Measurement slender, Bucket, Cotton cloths, Glass wares, Surgical blade, Scalpel blade holder, Scissors, Towels, Stethoscope, Thermometer, Timer, distilled water, Cotton wool, Chemical reagents (Methanol, Chloroform.).

\subsection{Plant Materials}

Moringa oleifera leaf was obtained from danchadi, Bodinga LGA. The plant was identified at the Herbarium, Department of Biological Science, in Usmanu Danfodiyo University Sokoto. Leaf was washed thoroughly with clean water and allowed to dry at room temperature for two to three weeks. It was then crushed into semi-powder form using laboratory mortar and pestle. The dried powdered leaf was then used for further study.

\subsection{Preparation of Plant Extracts}

The leaf of Moringa oleifera was thoroughly rinsed in tap water to remove any residual dirt's, dried at room temperature for two to three weeks and then crushed into semi-powder. A $0.5 \mathrm{~kg}(500 \mathrm{~g})$ of the grinded leaf was extracted using $99.5 \%$ Methanol ( 2 liter) and 4 liter of distilled water. Grounded leaf was soaked into the $80 \%$ methanol and kept at room temperature under monitored for three days and then filtered using soft cotton cloths. Filtered was then concentration in vacuole at 50 degree Celsius using rotary evaporator and subsequently freeze dried. The yield of freeze dried sample representing the aqueous extract was obtained.

\subsection{Experimental Animals}

Twenty Wistar albino rats of approximately five (5) weeks old and weighing between 120-200g were used for the study. The rats were obtained from the Animal House at the Department of Pharmacology and Toxicology, Usmanu Danfodiyo Teaching Hospital Sokoto. The animals were house in sanitary cage and had access to tap water and a standard diet (rat pellets). The room temperature was controlled at 25 to 28 Degree Celsius. All procedures involving the animals were conducted with strict adherence to the guidelines and procedure provided by the animal ethics committee.

\subsection{Experimental Design}

The leaf extract was administered orally once using a cannula attached to the $5 \mathrm{ml}$ syringe. And the rats' vital parameters were monitored and recorded every two hours for the first eight hours and there after four-hour interval for twenty-four hours.

Group 1 (5 rats) received Moringa oleifera leaf extracts at dose rate of $2000 \mathrm{mg} / \mathrm{kg} \mathrm{B}$. W.

Group 2 (5 rats) received Moringa oleifera leaf extracts at dose rate of $1000 \mathrm{mg} / \mathrm{kg} \mathrm{B}$. W.

Group 3 (5 rats) received Moringa oleifera leaf extracts at dose rate of $500 \mathrm{mg} / \mathrm{kg} \mathrm{B}$. W.

Group 4 (5 rats) (control group) was given tap water only.

The responses to be observed will include those related to vision, body temperature, respiratory rate, heart rate, animal activity and consciousness. The effect on vision would be ensured critical examination to see whether the animal will failed to avoid a pointer brought closer to its eyes. Body temperature was measured by inserting thermometer in to the rectum and held for $1 \mathrm{~min}$. Heart rate was measure using stethoscope for $1 \mathrm{~min}$. Behavior for the activity and consciousness was measured by monitoring the behaviors of the animals.

\subsection{Statistical Analysis}

The data obtained were analyzed using microsoft office Excel 2007 and Statistical Package used was Graph prism version 5.0. Results were expressed as mean \pm SD and presented in tabular form. The result of physiological vital parameter including body temperature, respiratory rate and heart rate obtained from the experimental groups were compared with the of control groups using paired analysis of variance (ANOVA).

\section{Results}

\subsection{Effects of Aqueous Leaf Extracts of Moringa oleifera on Temperature $\left({ }^{\circ} \mathrm{C}\right)$}

The effects of crude extract on the Physiological vital 
parameters of Wistar albino rats shows slight variation in temperature between the control group and the group exposed to different concentration of the crude extract. Significant difference at 0.05 was observed between the group exposed to $2000 \mathrm{mg} / \mathrm{kg}$ and control group (Figure 1).

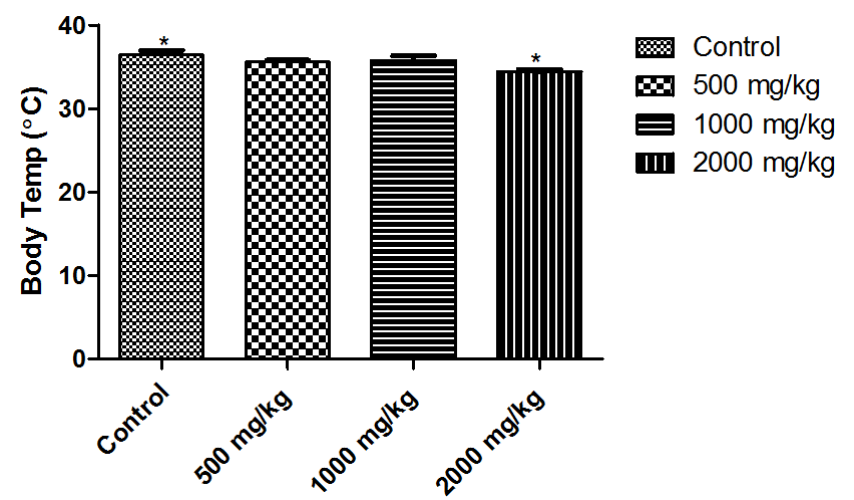

Figure 1. Effect of Moringa oleifera (leaf) extract at different concentration (500-2000 $\mathrm{mg} / \mathrm{mL}$ ) on body temperature of experimentally exposed Wister rats. The increase body temperature is shown versus concentration of the tested crude extracts and control. The values represent mean $\pm S D$ from three independent experiments $(n=3)$.

\subsection{Effects of Crude Extract on Heart Rate (Beat per Minutes) of Wistar Albino Rats}

The effects of crude extract on the Physiological vital parameters of Wistar albino rats shows variation in heart rate between the control group and the group exposed to different concentration of the crude extract. Significant difference at 0.001 was observed between the group exposed to 500 $\mathrm{mg} / \mathrm{kg}, 1000 \mathrm{mg} / \mathrm{kg}$ and $2000 \mathrm{mg} / \mathrm{kg}$ and control group (Figure 2).

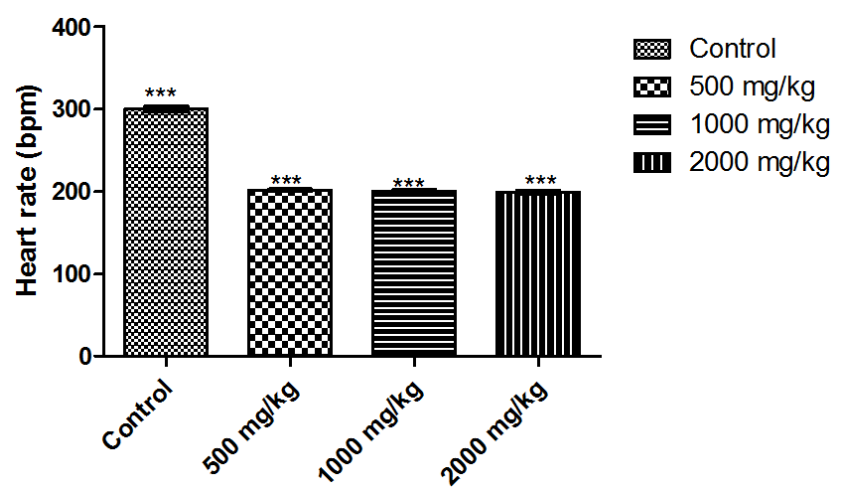

Figure 2. Effect of Moringa oleifera (leaf) extract at different concentration (500-2000 $\mathrm{mg} / \mathrm{mL})$ on heart rate of experimentally exposed Wister rats. The increase heart rate is shown versus concentration of the tested crude extracts and control. The values represent mean $\pm S D$ from three independent experiments $(n=3)$.

\subsection{Effects of Crude Extract of on Respiratory Rate (Cycle per Minutes)}

The effects of crude extract on the Physiological vital parameters of Wistar albino rats shows variation in respiratory rate between the control group and the group exposed to different concentration of the crude extract.
Significant difference at 0.01 was observed between the group exposed to $500 \mathrm{mg} / \mathrm{kg}$ and control group. There is a significant difference at 0.001 between the group exposed to $2000 \mathrm{mg} / \mathrm{kg}$ and the groups exposed to $1000 \mathrm{mg} / \mathrm{kg}, 500$ $\mathrm{mg} / \mathrm{kg}$ and the control group (Figure 2).

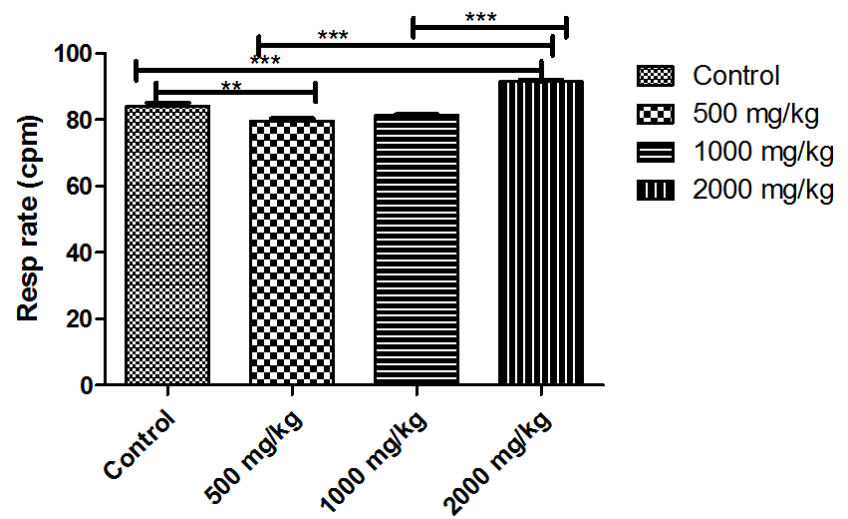

Figure 3. Effect of Moringa oleifera (leaf) extract at different concentration $(500-2000 \mathrm{mg} / \mathrm{mL})$ on respiratory rate of experimentally exposed Wister rats. The increase respiratory rate is shown versus concentration of the tested crude extracts and control. The values represent mean $\pm S D$ from three independent experiments $(n=3)$.

\section{Discussion}

The study undertook to evaluate the acute toxicity of the Moringa oleifera $80 \%$ leaf extract on rat model. To the time of this write up, there was no online data on the effects of Effect of Moringa oleifera plant extracts on animal vital parameters. Several studies on the effect of crude extracts on vital parameters were reported. This include metabolite regulatory interactions control plant respiratory metabolism via target of rapamycin (tor) kinase activation [8], biochemical and hematological effect of cordyla pinnata following acute and sub-acute exposure to rattus norvegicus [9]. There is slight variation in temperature between the control group and the group exposed to different concentration of the crude extract. This result disagree with the finding reported by Arunsi et al., which shows no variation in temperature following administration of Aspilia africana leaves ethanolic extract to rat model in the Evaluation of the acute and sub-acute toxicity study [10]. There was no scientific explanation on how crude extract affects body temperature. Altered metabolic activities due to changes in feed or medicinal effects of the crude extract may be responsible for the increased in body temperature [11]. Variation in heart rate between the control group and the group exposed to different concentration of the crude extract. This finding is in line with one reported by joseph et al., whose observed potential of Moringa oleifera to cause increase in heart rate following administration to rat in cardio protective study [12]. Scientist revealed the potential of several phenolic compounds to synergistically caused increase heart and respiratory rate due to the cardiac stimulant effect of several compounds [13]. 


\section{Conclusion}

The present study showed that $80 \%$ leaf extract of Moringa oleifera possessed anti-hypertensive properties in Wistar rats which suggest the presence of biologically active components which may be worth further investigation and elucidation. There is need for phytochemical study to identify and isolate the biological compound with anti-hypertensive properties.

\section{References}

[1] Asomugha, A. L., Ezejindu, D. N., Asomugha, R. N., Anyabolu, A. E., \& Ojukwu, P. C. (2015). Evaluation of toxicity effect of graded doses of Moringa oleifera leaf extract on blood indices using 20 adult Wistar rats. Int J Biom Adv Res, $6(2), 98-102$.

[2] MASIH, L. P., Singh, S., Elamathi, S., Anandhi, P., \& Abraham, T. (2019). Moringa: A Multipurpose Potential CropA Review. Proceedings of the Indian National Science Academy, 85 (3), 589-601.

[3] Balusamy, S. R., Perumalsamy, H., Ranjan, A., Park, S., \& Ramani, S. (2019). A dietary vegetable, Moringa oleifera leaves (drumstick tree) induced fat cell apoptosis by inhibiting adipogenesis in 3T3-L1 adipocytes. Journal of Functional Foods, 59, 251-260.

[4] Tété-Bénissan, A., Quashie, M. A., Lawson-Evi, K., Gnandi, K., Kokou, K., \& Gbeassor, M. (2013). Influence of Moringa oleifera leaves on atherogenic lipids and glycaemia evolution in HIV-infected and uninfected malnourished patients. Journal of Applied Biosciences, 62, 4610-4619.

[5] Ezzat, S. M., El Bishbishy, M. H., Aborehab, N. M., Salama, M. M., Hasheesh, A., Motaal, A. A., ... \& Metwally, F. M. (2020). Upregulation of MC4R and PPAR- $\alpha$ expression mediates the anti-obesity activity of Moringa oleifera Lam. in high-fat diet-induced obesity in rats. Journal of Ethnopharmacology, 112541.
[6] Jacques, A. S., Arnaud, S. S., Fr\&ejus, O. O., \& Jacques, D. T. (2020). Review on biological and immunomodulatory properties of Moringa oleifera in animal and human nutrition. Journal of Pharmacognosy and Phytotherapy, 12 (1), 1-9.

[7] Aponso, M., Patti, A., \& Bennett, L. E. (2020). Dose-related effects of inhaled essential oils on behavioural measures of anxiety and depression and biomarkers of oxidative stress. Journal of Ethnopharmacology, 250, 112469.

[8] O'Leary, B. M., Oh, G. G. K., Lee, C. P., \& Millar, A. H. (2020). Metabolite regulatory interactions control plant respiratory metabolism via Target of Rapamycin (TOR) kinase activation. The Plant Cell, 32 (3), 666-682.

[9] Alawode, A. R., Dauda, M., Adegbola, A. G., \& Babatunde, O. R. (2020). Biochemical and Hematological Effect of Cordyla pinnata Following Acute and Sub-Acute Exposure to Rattus norvegicus. Iranian Journal of Toxicology, 14 (1), 43-50.

[10] Arunsi, U. O., Chinyere, G. C., Ngwogu, K. O., Ngwogu, A. C., Atasie, O. C., Oti, U. A., ... \& Ibe, C. (2020). Evaluation of the biochemical, haematological and histopathological parameters of female Wistar rats fed with aqueous and ethanol extracts of Aspilia africana leaves. Journal of Herbmed Pharmacology, 9 (3).

[11] Schwachtje, J., Whitcomb, S. J., Firmino, A. A. P., Zuther, E., Hincha, D. K., \& Kopka, J. (2019). Induced, Imprinted and Primed Metabolic Responses of Plants to Changing Environments: Do Plants Store and Process Information by Metabolic Imprinting and Metabolic Priming. Frontiers in plant science, 10, 106.

[12] Randriamboavonjy, J. I., Loirand, G., Vaillant, N., Lauzier, B., Derbré, S., Michalet, S., ... \& Tesse, A. (2016). Cardiac protective effects of Moringa oleifera seeds in spontaneous hypertensive rats. American journal of hypertension, 29 (7), 873-881.

[13] Minatel, I. O., Borges, C. V., Ferreira, M. I., Gomez, H. A. G., Chen, C. Y. O., \& Lima, G. P. P. (2017). Phenolic compounds: Functional properties, impact of processing and bioavailability. Phenolic Compounds Biological Activity. Ed. InTech. Rijeka, Croatia, 1-24. 